\title{
Optimal Operation and Size for an Energy Hub with CCHP
}

\author{
Aras Sheikhi, Ali Mohammad Ranjbar, Hashem Oraee, Amir Moshari \\ Department of Electrical Engineering, Sharif University of Technology, Tehran, Iran \\ E-mail:Aras.Sheikhi@yahoo.com \\ Recieved September 29, 2011; revised October 24, 2011; accepted November 5, 2011
}

\begin{abstract}
The interest in distributed generation has been increasing in recent years, especially due to technical development on generation systems that meet environmental and energy policy concerns. One of the most important distributed energy technologies is Combined Cooling, Heat and Power (CCHP) systems. CCHP is a small and self-contained electric, heating and cooling generation plant that can provide power for households, commercial or industrial facilities. It can reduce power loss and enhance service reliability in distribution systems. The proposed method in this paper determines the optimal size and operation of CCHP, auxiliary boiler and also heat storage unit as elements of an energy hub, for users by an integrated view of electricity and natural gas network. Authors apply cost and benefit analysis in the optimization. To confirm the proposed method, the optimum sizes of these elements are determined for a hotel in Tehran as a case study.
\end{abstract}

Keywords: Combined Cooling Heating and Power (CCHP), Cost and Benefit Analysis, Energy Hub, Optimal Operation, Optimal Size

\section{Introduction}

The electric power industry is under deregulation in response to changes in legislation, technology, market and competition. One of the main advantages of deregulation is that it can increase the efficiency of industrial and commercial sectors and reduce the cost of electrical energy for all customers [1].

Deregulation has evolved in all three sectors of the power system (i.e. generation, transmission, and distribution) from centralized to a decentralized status. One of the main concepts in deregulation is Microgrids which are used at the distribution level [2]. Microgrid, with its decentralized electricity generation, combined with onsite production of heat and cooling, could provide reliable electric power as well as heat and cooling to its consumers at an economic cost. This set is named combined cooling, heat and power (CCHP) system.

Nowadays, following the expansion of natural gas networks and also benefits of this energy carrier such as lower emission level and prices, CCHP technologies have attained unprecedented level of popularity as one of the most important distributed energy resources [3].

One of the major factors for users on choosing a CCHP system is the overall costs of CCHPs which is largely dependent on its size [4]. Hence finding the op- timized size of a CCHP is economically important.

Generally, an optimized CCHP can be evaluated by analyzing two main factors: costs and benefits. Cost is one of the main components in nearly all DG evaluations, but is inadequate for complete evaluations. Furthermore, reliability enhancements [5], power cost saving, power loss and emission reduction [6] are also key elements in deciding which CCHP should be installed.

The cost of generation of electricity and heat from a CCHP can be classified into capital investment cost, operation and maintenance (O\&M) costs and fuel cost. On the other hand, the benefits from the CCHP placement can be classified into power cost and power loss reducetion and significantly decreasing the expected energy not supplied which is a favorable effect in a power system.

CCHP can inject its power directly into distribution feeders and by alleviating transmission losses the benefits of power loss reduction become quite clear [6]. Moreover reliability enhancement has received substantial attentions as it reduces the costs of losses incurred by utility customers as a result of power failures [7].

All of these costs and benefits are calculated in terms of present value factor (PVF), accumulated over the economic life of the respective equipment. It is common practice for a decision maker to translate future cash flows into their present values. 
From a number of recent publications [1-16], it can be seen that in a deregulated power system, each individual distribution company may wish to determine the costs and benefits of DG planning under different circumstances. It is difficult to find a single planning method that satisfies all the company objectives simultaneously. In this paper a value-based planning method for CCHP placement based on the energy hub concept is proposed. The proposed method takes the benefits and costs of CCHP placement into account and determines the optimal sizing and operation for an energy hub's elements. Test results show that with proper size selection, CCHP placement can reduce the running cost of a multicarrier energy system.

The contents of this paper are organized into the following six sections.

Determination the optimum operational point, the energy hub concept and a brief overview of the Energy hub modeling is presented in Section II. Section III discusses the potential benefits of deploying energy hubs. Section IV provides detailed formulations of the problem and case studies are debated in detail in section V. Finally, conclusions are drawn in Section VI.

\section{Energy Hub Concept and Modeling}

Some conceptual approaches for an integrated view of transmission and distribution systems with distributed generation have been published. Besides "energy-services supply systems" [17], "basic units" [18], and "micro grids" [19], so-called "hybrid energy hubs", are suggested, where the term "hybrid" represent the use of multiple energy carriers [20,21]. An energy hub is considered a unit where different energy carriers can be converted, conditioned, and maybe stored. It represents an interface between different energy infrastructures and/or loads. Energy hubs consume power at their input ports which is connected to, e.g. electricity and natural gas infrastructures, and perform certain required energy services such as electricity, heating, cooling, and compressed air at their output ports [4].

Energy hubs include two basic elements: direct connections and converters. Direct connections are used to deliver an input power to the output without converting. Converter elements are used to change carriers into other forms or qualities. Such as gas turbines, combustion engines or fuel cells. Figure 1 demonstrates an example of an energy hub.

The components within the hub may create extra connections between inputs and outputs. For instance, the electrical load connected to the hub in Figure $\mathbf{1}$ can be met by consuming all power directly from the electricity grid or generating part or all of the required electricity

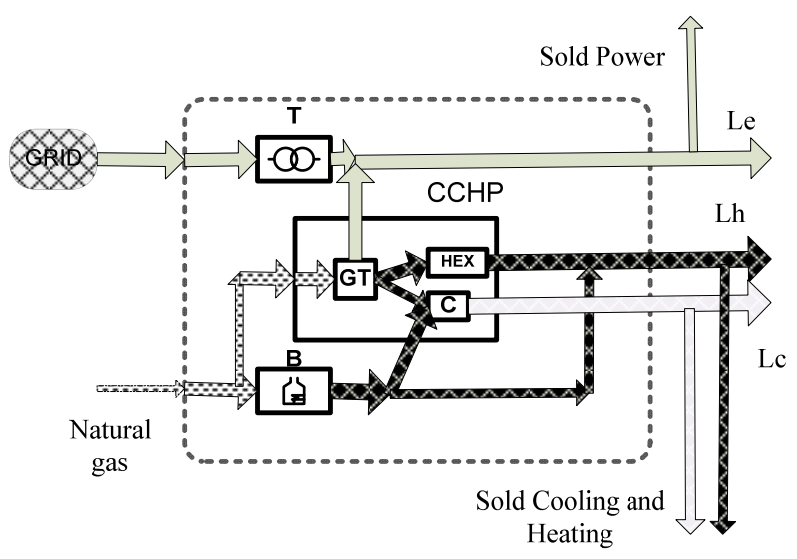

Figure 1. An energy hub containing an electric transformer, a CHP, a boiler (B) an absorption chiller (C): and Heat Exchanger (HEX).

from natural gas. This redundancy in supply results in a significant benefit, which can be achieved using energy hubs: Reliability of supply can be enhanced from the load's perspective because it is not completely dependent on a single supply.

From a system point of view, combining and coupling different energy carriers show a number of potential benefits over conventional, decoupled energy supply.

The energy hub is an archetype with no limitations to the size of the modeled system. Single power plants or industrial buildings as well as bounded geographical areas such as entire towns can be modeled as energy hubs. The model of the system is formulated below.

In the system under study, the energy hub represents a general consumer as a household which uses both electricity and gas. The hub is connected to a large gas network and the electricity network.

The hub consumes electric power $P_{e}$ and gas $P_{g}$ and provides energy to its electric load $L_{e}$, heating load $L_{h}$ and cooling load $L_{c}$. The hub contains conversion technologies in order to fulfill their energy load requirements. For energy conversion, the hub contains a CCHP and an auxiliary boiler. The CCHP device couples the three energy systems at the same time that produces electricity, cooling and heat from natural gas. Depending on the prices of energy and load profiles, the CCHP device is utilized differently. At high electricity prices, the electric load is supplied by CCHP for longer times. The produced heat is then used to supply the thermal load. At low electricity prices, the electric load is rather supplied directly by the electricity network and the gas is used for supplying the thermal load via the boiler house. Hence, there are several ways in which electric and thermal load demands can be met. This redundancy increases the reliability of supply overtly and simultaneously provides the possibility for optimizing the input energies, e.g. using 
criteria such as cost, availability, emissions, etc.

Consider a converter device as depicted in Figure 2 that converts an input energy carrier $\alpha$ into $\beta$. Input and output power flows are not independent; they are considered to be coupled,

$$
L_{\beta}=c_{\alpha \beta} \times P_{\alpha}
$$

where $P_{\alpha}$ and $L_{\beta}$ are the steady state input and output energy flows respectively, $c_{\alpha \beta}$ is the coupling factor which defines the coupling between input and output energy flow. For a simple converter device with one input and one output, the coupling factor corresponds to the converter's steady state energy efficiency.

A general model covering all types of couplings can be stated all power inputs $P_{\alpha}, P_{\beta}, \cdots, P_{\omega}$ and outputs $L_{\alpha}, L_{\beta}, \cdots, L_{\omega}$ in vector form and enables the formulation of a multi-input, multi-output power conversion as follow [7]:

$$
\left[\begin{array}{c}
L_{\alpha} \\
L_{\beta} \\
\vdots \\
L_{\omega}
\end{array}\right]=\left[\begin{array}{cccc}
C_{\alpha \alpha} & C_{\beta \alpha} & \cdots & C_{\omega \alpha} \\
C_{\alpha \beta} & C_{\beta \beta} & \cdots & C_{\omega \beta} \\
\vdots & \vdots & \ddots & \vdots \\
C_{\alpha \omega} & & & C_{\omega \omega}
\end{array}\right]\left[\begin{array}{c}
P_{\alpha} \\
P_{\beta} \\
\vdots \\
P_{\omega}
\end{array}\right]
$$

\section{Proposed Optimization Method}

In this study, CCHP has a central role in the energy hub. Hence investigating the best size of CCHP as the most important elements of an energy hub system has a substantial effect on the users' benefits.

This section proposes an analytical method to determine the most advantageous selection.

To find the best elements of the energy hub between existing choices the value based planning will be employed. The costs of CCHP placement include the investment, maintenance and operation cost (O\&M) of CCHP, auxiliary boiler and storage devices. To find the benefit term for CCHP placement, it is assumed that the outputs of CCHP are sold completely. Emission reducetion is the other major term that would be added to form the total benefit. This planning method attempts to realize the minimum cost solution where the total benefits can be maximized.

The total input flow $P_{g}$ splits up to different converters, CCHP and auxiliary boiler in Figure 1. Dispatch factor, $\gamma$, specifies how much of the total input power $P_{g}$ flows through the CCHP. At the same time, absorption chiller uses heating power to generate cooling. $\alpha, \beta$ show the

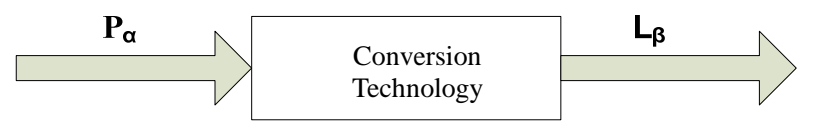

Figure 2. Model of energy converter. proportion of heating power that is produced by auxiliary boiler and CHP, consumed by the chiller.

To investigate optimal value of this parameter, an appropriate objective function which is considered the net benefit for the energy hub system has to be formed.

The threat of global warming and climate change has created worldwide concerns. As a result, many countries have reached and signed agreements such as Kyoto in order to reduce greenhouse gas emissions. Hence, $\mathrm{CO}_{2}$ emission consideration is highlighted as one of the effecttive factors on power generation. To model this factor $\chi_{e}$ and $\chi_{g}$ are introduced. These parameters convert $\mathrm{CO}_{2}$ emissions of electricity and natural gas, as the energy hub input, into dollars.

Based on the social costs of carbon emissions, it is assumed that the price of carbon is around $\$ 30$ per ton (\$0.03 per $\mathrm{kg}$ ) which needs to increase with inflation rates [22].

With these extensions, multi-period multi-carrier optimal power flow and limitations can be stated as nonlinear programming (NLP) structure:

$$
\begin{gathered}
L_{e}(n)+P_{s e}(n)=\eta_{e e} P_{e}(n)+\gamma(n) \eta_{g e}^{\mathrm{CHP}} P_{g}(n) \\
L_{h}(n)+H_{\text {se }}(n) \\
=\left((1-\gamma(n)) \alpha(n) \eta_{g h}^{B}+\beta(n) \gamma(n) \eta_{g h}^{\mathrm{CHP}}\right) P_{g} \\
-S_{\text {inh }}(n)+S_{\text {outh }}(n) \\
L_{c}(n)+C_{\text {se }}(n)=\left((1-\gamma(n))(1-\alpha(n)) \eta_{g h}^{B}\right. \\
\left.+(1-\beta(n)) \gamma(n) \eta_{g h}^{\mathrm{CHP}}\right) \eta_{h c}^{\text {chiller }} P_{g} \\
+S_{\text {outc }}(n) \eta_{h c}^{\text {chiller }} \\
S(n)=0.98 \times S(n-1)+S_{\text {inh }}(n)-S_{\text {outh }}(n)-S_{\text {outc }}(n) \\
S_{\text {in }}(n) \leq \operatorname{Maximum~heat~input~} \quad \mathrm{kW} / \mathrm{h}_{S_{\text {out }}(n) \leq \operatorname{Maximum~heat~output~} \mathrm{kW} / \mathrm{h}} \\
S(n) \leq S_{m} \\
P_{g}^{\min } \leq P_{g} \leq P_{g}^{\max } \\
P_{e}^{\min } \leq P_{e} \leq P_{e}^{\max } \\
P_{\text {se }}(n) \leq P_{\text {semax }} \\
H(n) \leq H_{\max } \\
C(n) \leq C_{\max } \\
0 \leq \gamma, \alpha, \beta \leq 1 \\
\gamma(n) \times P_{g}(n) \leq \mathrm{CHP} \text { Capacity } \\
(1-\gamma(n)) \times P_{g}(n) \leq \mathrm{Auxilary} \text { Boiler Capacity }
\end{gathered}
$$




$$
\begin{aligned}
& \left((1-\gamma(n))(1-\alpha(n)) \eta_{g h}^{B}\right. \\
& \left.+(1-\beta(n)) \gamma(n) \eta_{g h}^{\mathrm{CHP}}\right) \eta_{h c}^{\text {chiller }} P_{g} \leq \text { Chiller Capacity } \\
& Z=\sum P_{e}(n) e(n)+P_{g}(n) g(n)+P_{e}(n) \chi_{e}+P_{g}(n) \chi_{g}
\end{aligned}
$$

The cost heat pumped in to the heating storage devices is neglected.

where:

$L_{e}$ is electrical load;

$L_{h}$ is heating load;

$\gamma$ is dispatch factor;

$\eta_{e e}$ is the transformer efficiency;

$\eta_{g h}^{B}$ is the boiler efficiency;

$\eta_{h c}^{\text {Chiller }}$ is the chiller efficiency;

$\eta_{g e}^{\mathrm{CHP}}$ is the electrical efficiency of CHP;

$\eta_{g h}^{\mathrm{CHP}}$ is the heating efficiency of CHP;

$e(n)$ is the electricity price $(\$ / \mathrm{kWh})$;

$g(n)$ is the cost of natural gas $(\$ / \mathrm{kWh})$;

$S_{m}$ is the capacity of heat storage;

$S_{\text {in }}$ is the input rate of heat storage;

$S_{\text {out }}$ is the output rate of heat storage;

$P_{s e}$ is the electricity transferred from CHP to the electric grid;

$C(n)$ is the sold cooling power;

$H(n)$ is the sold heating power;

$Z$ is the cost of consuming natural gas and electricity of energy hub input;

$b$ is the bonus for exporting electricity from CHP to the electric grid.

Using CHP to produce electricity eliminates the cost of transmission and this is one of the important factors that make CHP as an economically attractive option for governments to produce electricity. Decreasing the cost of transmission dose not benefit the end users directly and is a beneficial factor for governments. To make end users share this benefit, governments provide some bonus schemes for electricity producers by distributed generation, that this bonus has been added to the base price of electricity exported to the grid.

Finding this added value need some calculations and suppositions as follow:

The effective efficiency considered as follows and it must be more than the mean efficiency of conventional power generation.

$$
\eta_{E}=\frac{\eta_{e}}{1-\left(\eta_{t} \times \mu\right)}
$$

\footnotetext{
$\eta_{E}$ : Effective efficiency;

$\eta_{e}$ : Electrical efficiency;

$\eta_{t}$ : Thermal efficiency;

$\mu$ : Percentage of the used heat of CHP.
}

The value of saving natural gas when CHP is used to produce $1 \mathrm{kWh}$ of electricity is calculated as follow:

$$
S G=\left[\frac{860}{H V_{g}} \times\left(\frac{100}{\eta_{\text {ave }}(1-L)}-\frac{100}{\eta_{E}}\right)\right]
$$

where:

$S G$ : saving natural gas when $1 \mathrm{kWh}$ of electricity generated by CHP instead of conventional power generation system $\left[\mathrm{m}^{3}\right]$

$H V_{g}$ : Heating value of natural gas $\left[\mathrm{kcal} / \mathrm{m}^{3}\right]$ tion

$\eta_{\text {ave }}$ : mean efficiency of conventional power genera-

$L$ : percentage of transmission loss of electrical grid

Multiplying the natural gas price by the above value results in the bonus that would be added to the base price of electricity:

$$
b=S G \times \text { natural gas price }
$$

Note that the feasible region of the optimization problem is defined by different constraints. An equality constraint is given by the equation that describes the power flow through the hub. Inequalities arise from limitations of the hub's input power vector and the power inputs to the individual converters. The relation between the hub input vector, the converter input vector and the amount of heat in the heating storage devices are given by (3), (4), (5) and (6). Maximum output and input heat transfer rate, lower and upper limits of the main branch gas pipeline and transformer rates are defined in (7)-(11) respecttively. Maximum allowable values of heating, cooling and electrical power for sale are given by (12)-(14). Limitation of the dispatch factors in (15) has to be regarded as well. Inequalities (16)-(18) show constrains for maximum capacity of CCHP and auxiliary boiler.

Obviously, efficiency and size of energy hub elements considerably affect the optimum value of parameters $\left(P_{e}\right.$, $\left.P_{g}, \gamma, \alpha, \beta\right)$.

The main objective in this paper is to calculate the optimum size of CCHP, auxiliary boiler and heat storage device in an energy hub. The objective function of the problem is:

$$
\max \{\text { Benefit-Cost }\}
$$

Benefit $=$

$$
\begin{aligned}
& \sum\left(\left(L_{e}(n)+P_{s e}(n)-P_{e}(n)\right)\left(e(n)+\chi_{e}-\chi_{g}+b\right)\right. \\
& +\sum\left(L_{c}(n)+C(n)\right)(C C(n)) \\
& \left.+\sum\left(L_{h}(n)+H(n)\right)\left(\frac{g}{\eta_{g h}^{B}}\right)\right) \times \mathrm{CPVF}
\end{aligned}
$$


Cost $=$ CHP Cost + Boiler Cost

+ Absorption Chiller Cost $+\left(C_{m}+Z\right) \times \mathrm{CPVF}$

+ Heating Storage Cost+Fixed Cost

where

$C_{m}$ is the maintenance cost of CHP per year:

$C_{m}=365 \times$ maintenance cost per $\mathrm{kWh} \times \sum_{n=1}^{24} \gamma P_{g}(n)(26)$

$C C(n)$ is the cost of sold cooling power per hour

$\mathrm{CPVF}$ is the cumulative present value:

$$
\begin{gathered}
\mathrm{PVF}=\frac{(1+i f)}{(1+i r)} \\
\mathrm{CPVF}=\frac{(\mathrm{PVF})^{E L}-1}{\mathrm{PVF}-1}
\end{gathered}
$$

where ir, if and $E L$ are respectively the per unit (p.u) interest rate, p.u inflation rate and economic life of the equipment.

Fixed cost term in (22) consists of the cost of the central controller, load controllers, interfacing equipment and low voltage circuit breaker [26].

\section{Case Study}

The model presented in this paper has been applied to a hotel building in Tehran as an energy hub.

Hotels usually operate 7800 to 8760 hours yearly. Most hotels, particularly larger ones, have large annual electricity consumptions. They also have high thermal needs $[23,24]$. This translates into a high thermal to electrical ratio of about 1.2 for the average hotel [6,25], indicating hotels can beneficially recapture waste heat generated by a CHP system. The high number of operating hours and the rather constant electrical, heat and cooling loads make hotels suitable candidates for a CCHP system.

In this case study, operational costs of a 50,000 squarefeet hotel as an energy hub is calculated and used to select the best CCHP system.

Energy load profile and energy price [28-30] of this hotel is depicted as follow (Figures 3-6):

Note that in Figure 4 there are two load profiles. One of them denotes winter and autumn day load sample and the other indicates load profile of summer and spring days.

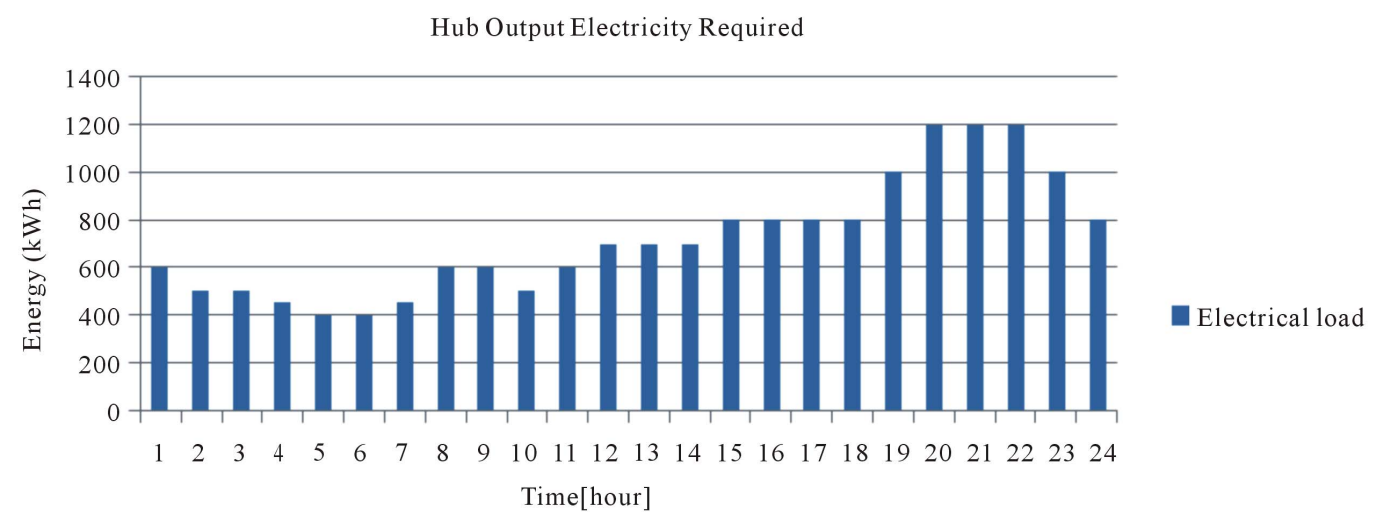

Figure 3. Electricity consuption in a normal day [summer and winter].

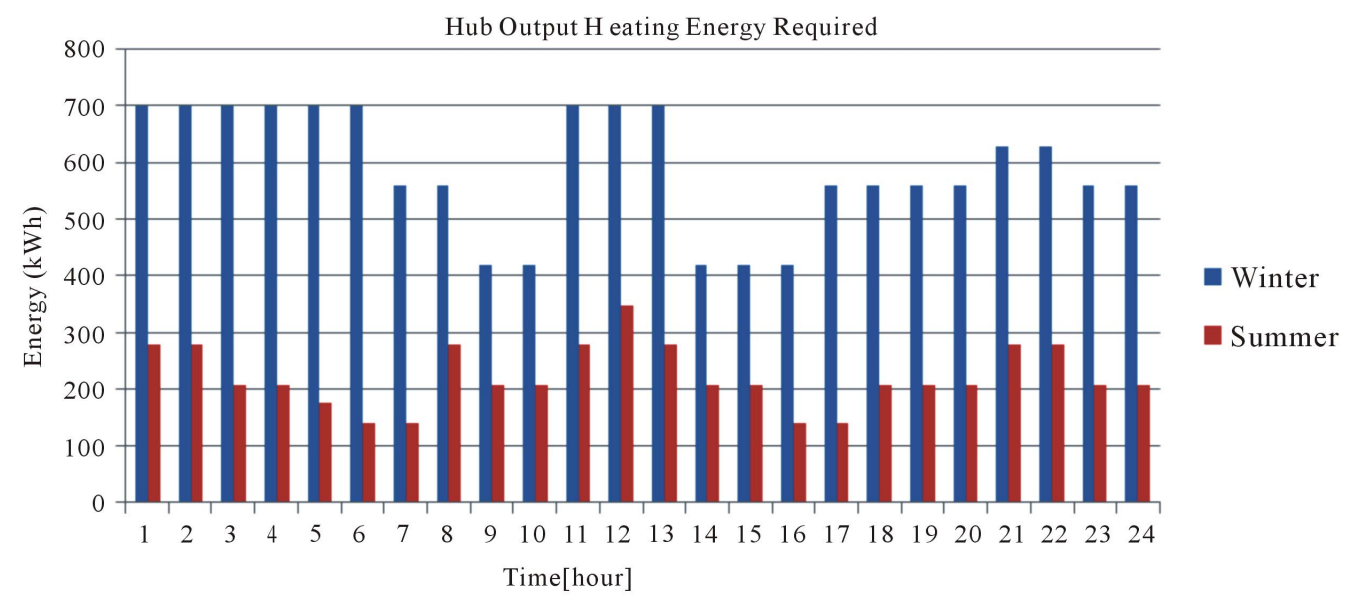

Figure 4. Heating energy consuption in a normal day [summer and winter]. 


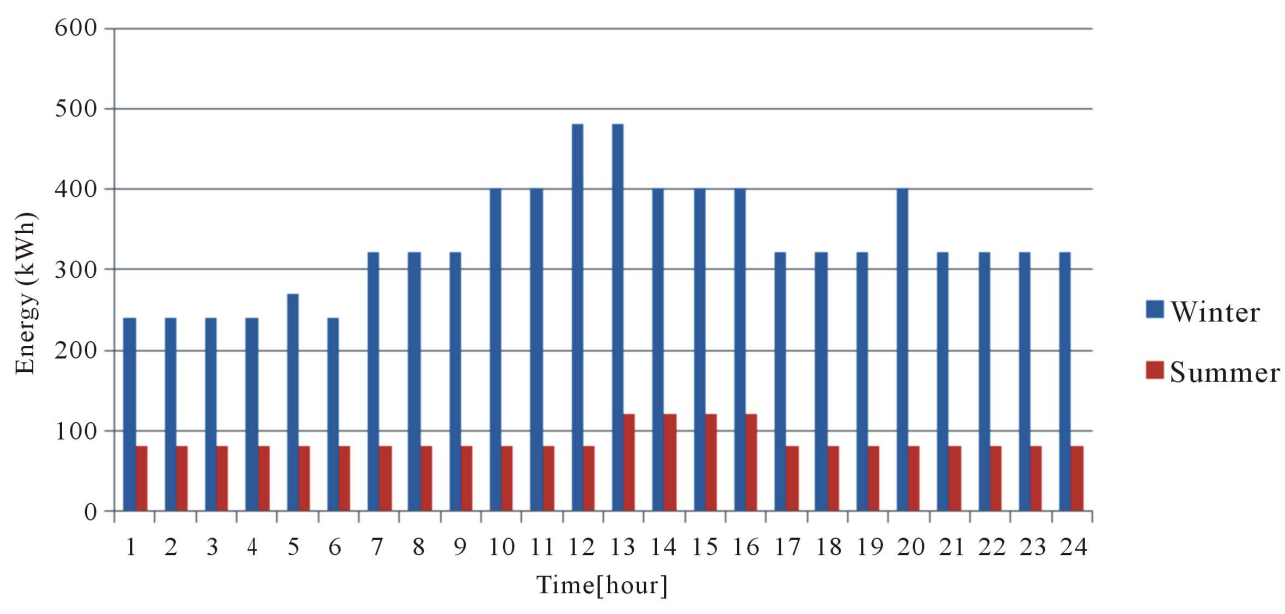

Figure 5. Cooling energy consuption in a normal day [summer and winter].

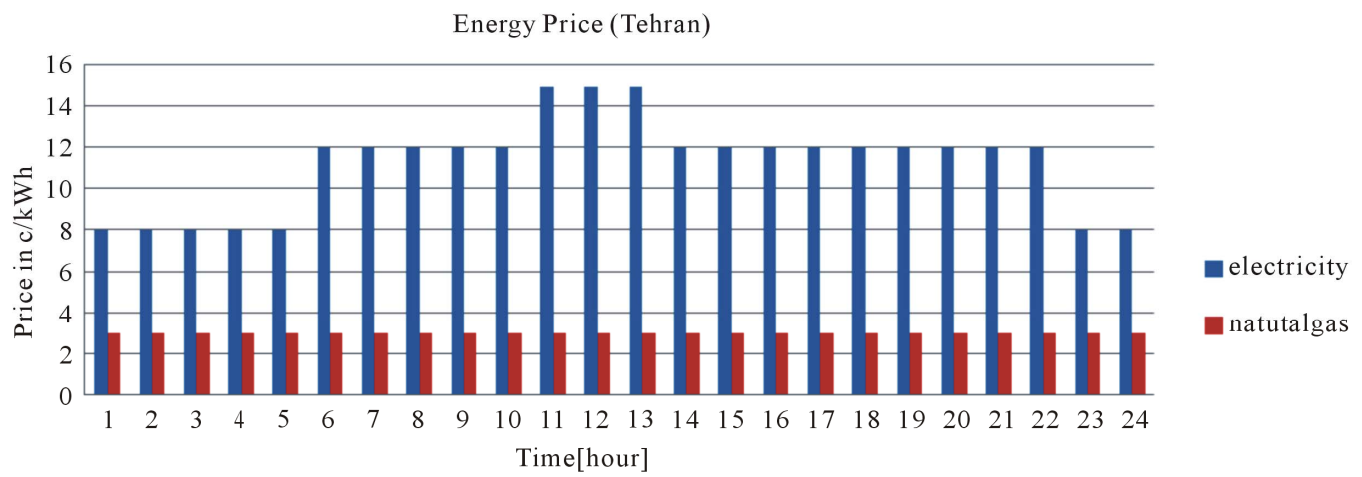

Figure 6. Energy price.

In this study, all efficiencies are independent of power and have a constant value. The typical energy distribution for internal combustion engines is provided [31]. It shows that $30 \%$ of the fuel energy is converted to heat energy rejected through the coolant and another $30 \%$ of the fuel energy is rejected as heat through the exhaust gas. The total efficiency of heat exchangers for the coolant and exhaust gas is estimated to be 0.85 , and the total fuel-to-thermal-energy conversion efficiency (i.e., total heat recovered from the engine) is then calculated to be, $(30 \%+30 \%)(0.85)=51 \%$.

The boiler thermal efficiency $\left(\eta_{g h}^{B}\right)$ is assumed to be $90 \%$. The total efficiency of the cooling components (chiller efficiency) was estimated by considering the Coefficient of Performance (CoP), amount of heat moved per unit of input work required, of an absorption chiller and the efficiency of an air handling unit.

A CoP of 0.7 is used for the absorption chiller and an efficiency of 0.85 is used for the air handling unit. The total efficiency of cooling components is then calculated to be $(0.7)(0.85) \times 100=60 \%$. The total efficiency of the heating components is estimated $85 \%$ which is an efficiency of the air handling unit.
The thermal energy losses due to energy transport/ transmission in the network are neglected in this simulation because the pipes are well insulated in the facility.

CHP and boiler costs depend of the size. Figures 7 and $\mathbf{8}$ depict these relations.

Tables 1 and 2 show the cost and performance characteristics of absorption chiller and heating storage devices [32]. Bonus for selling electricity to the grid is calculated by (22). The price of sold cooling is considered to be 1.2

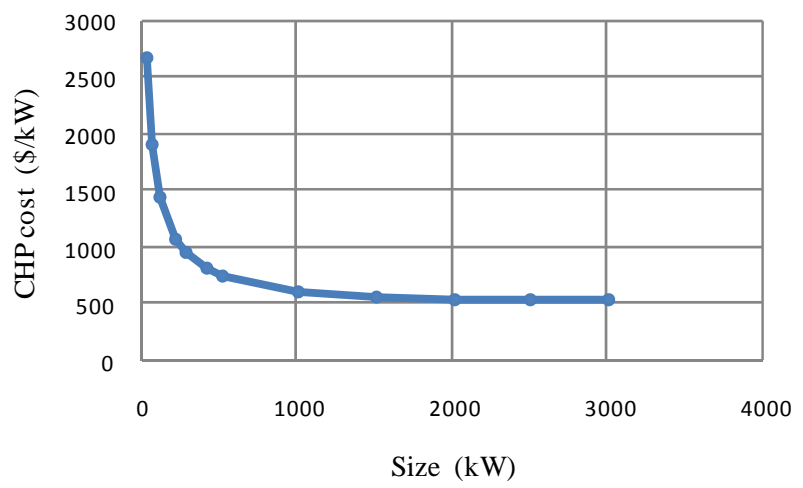

Figure 7. CHP cost. 


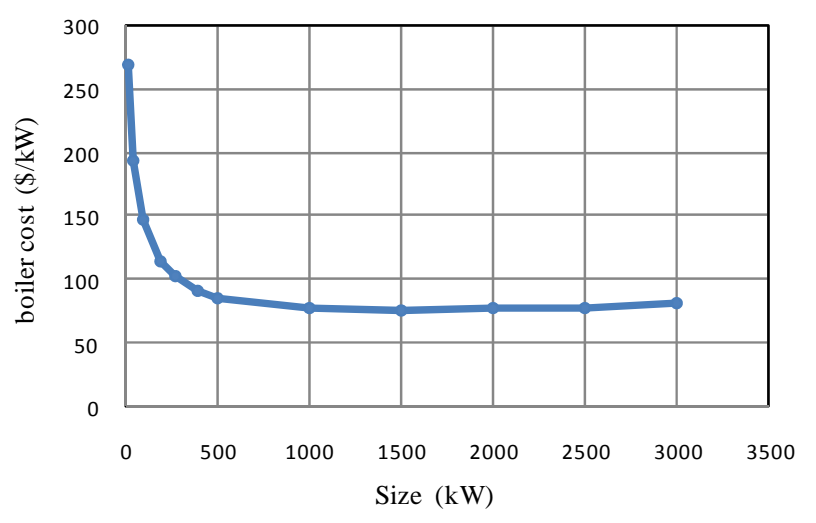

Figure 8. Boiler cost.

Table 1. Performance characteristics of CHP and auxiliary boiler.

\begin{tabular}{cccccccc}
\hline $\begin{array}{c}\text { Maintenance } \\
\text { Cost }(\$ / \mathrm{kWh})\end{array}$ & $\eta_{g e}^{\mathrm{CHP}}$ & $\eta_{g h}^{\mathrm{CHP}}$ & $\eta_{g h}^{B}$ & $\eta_{e e}$ & $\eta_{h c}^{\text {chiller }}$ & $\begin{array}{c}\mathrm{b} \\
\$ / \mathrm{kWh}\end{array}$ & $\begin{array}{c}\text { Fixed } \\
\text { Cost \$ }\end{array}$ \\
\hline 0.01 & $35 \%$ & $40 \%$ & $90 \%$ & $98 \%$ & $60 \%$ & 0.02 & 30,000 \\
\hline
\end{tabular}

Table 2. Cost of heating storage devices and absorption chiller.

\begin{tabular}{lll}
\hline & Thermal storage & Absorption chiller \\
\hline Fixed cost $(\$)$ & 10,000 & 20,000 \\
Variables cost $(\$ / \mathrm{kW})$ & 100 & 115 \\
\hline
\end{tabular}

times more than electricity price. A summary of energy hub elements' efficiency information for the algorithm and the data needed for optimization problem is listed in Table 1.

The boundary conditions are shows in Table 3.

The interest rate (ir) is 0.08 p.u., the inflation rate (if) is 0.05 p.u., the economic life cycle (EL) of all equipment is considered to be 15 years [26].

For Tehran $X_{e}=1.32 \$ / \mathrm{kWh}$ and $X_{g}=0.6 \$ / \mathrm{kWh}$ [27].
To solve the above problem, GAMS software is used and the best size of energy hub's elements is evaluated.

Table 4 demonstrates optimized values of energy hub elements.

$P_{e}$ equals zero at all times which indicates that the electrical loads have been supplied by CHP completely and Figure 9 shows the resulting $P_{g}$ as an optimal hub input.

No heating is sold by installing the CHP. On the other hand cooling is exported with the maximum power (160 $\mathrm{kW} / \mathrm{h}$ ) continuously. From Figure 10 it can be inferred that exported electricity from energy hub has same shape in winter and summer.

Figure 11 shows the stored heat for all 24 periods. Each bar represents the energy stored at the end of the period. The storage is assumed to be empty at the end of the period.

\section{Conclusions}

Competition is a key word in the deregulated market and it is in close association with the economy. The values of BCR greater than one in all cases of CHP indicate the economic viability of investment planning when CHPs

Table 3. Maximum value of parameters.

\begin{tabular}{ccccc}
\hline$P_{\text {emax }}(\mathrm{kW})$ & $P_{g \max }(\mathrm{kW})$ & $H_{\max }(\mathrm{kW})$ & $C_{\max }(\mathrm{kW})$ & $P_{\text {semax }}(\mathrm{kW})$ \\
\hline 1000 & 2500 & 200 & 160 & 200 \\
\hline
\end{tabular}

Note that the all parameters are positive.

Table 4. Optimized value of energy hub elements.

\begin{tabular}{ccccc}
\hline $\begin{array}{c}\text { Benefit-Cost } \\
\text { (Million \$) }\end{array}$ & $\begin{array}{c}\text { CHP } \\
\text { Capacity } \\
(\mathrm{kW})\end{array}$ & $\begin{array}{c}\text { Auxiliary } \\
\text { Boiler } \\
\text { Capacity (kW) }\end{array}$ & $\begin{array}{c}\text { Absorption } \\
\text { Chiller } \\
\text { Capacity (kW) }\end{array}$ & $\begin{array}{c}\text { Heating } \\
\text { Storage }\end{array}$ \\
\hline 2.48 & 948 & 296 & 366 & 30 \\
\hline
\end{tabular}

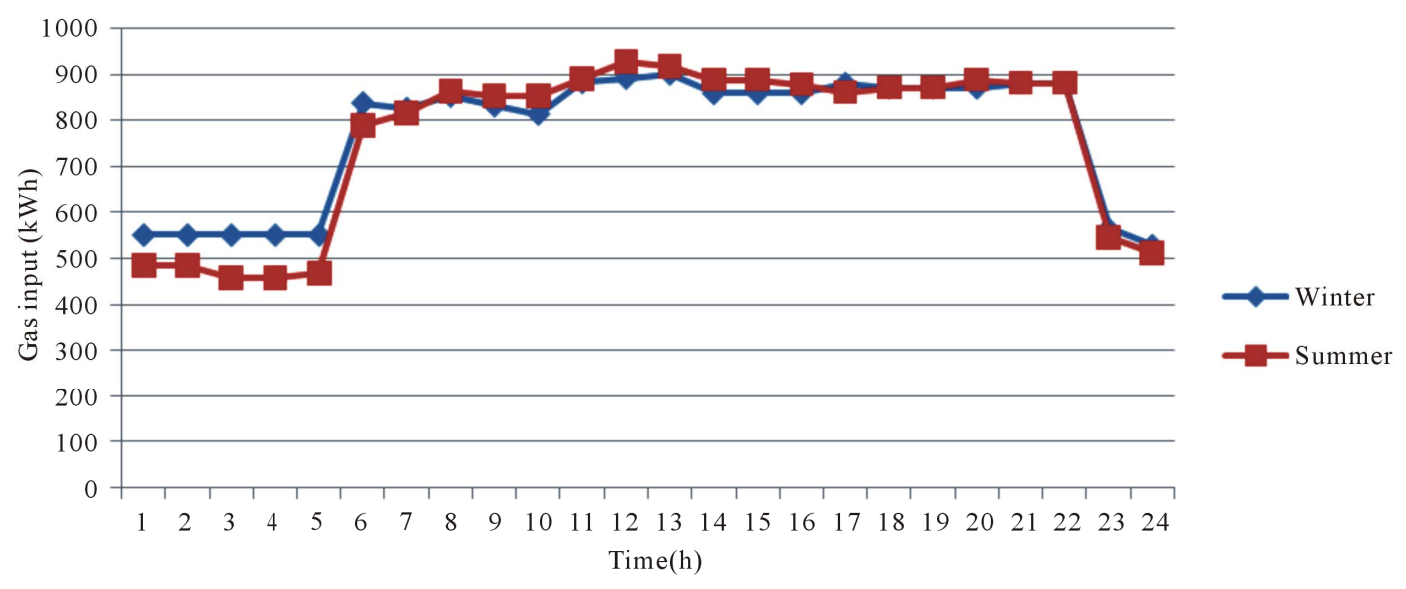

Figure 9. Input natural gas $\left(P_{g}\right)$. 


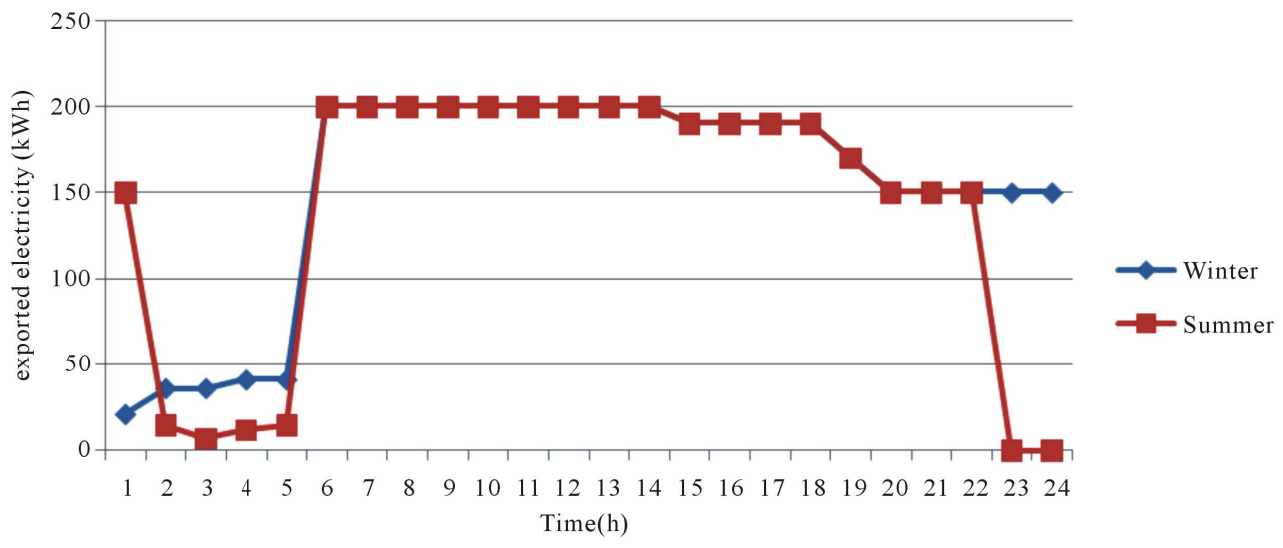

Figure 10. Exported electricity to the grid.

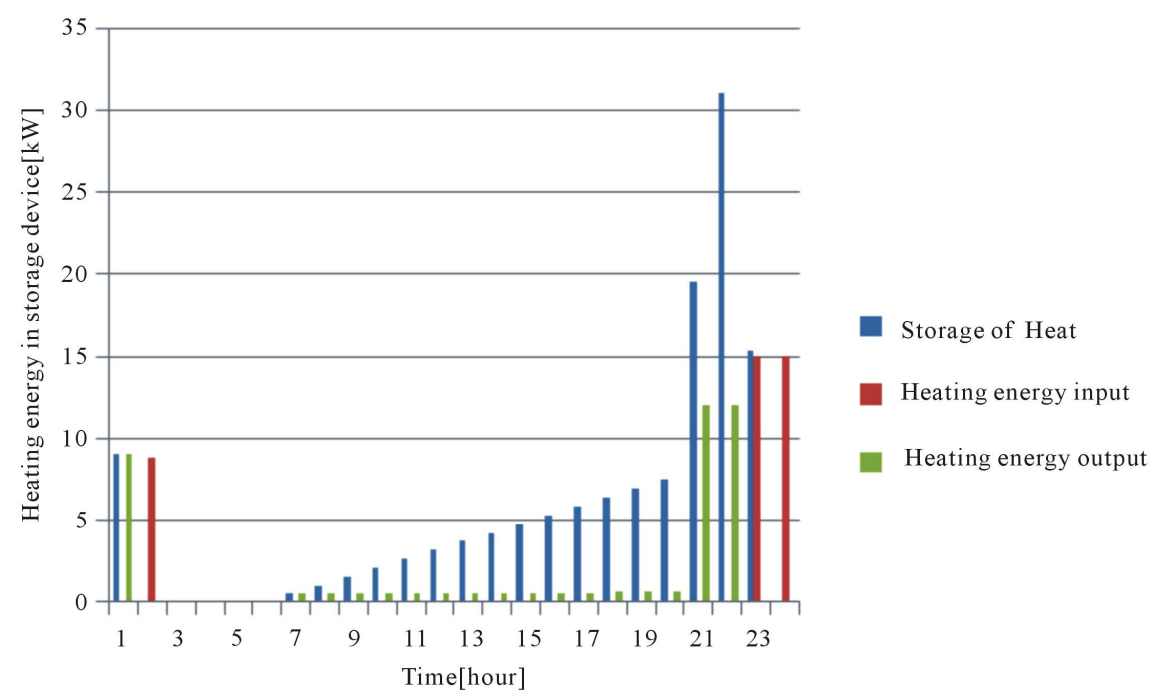

Figure 11. Input, output and storage of heating energy in storage device.

are deployed optimally in the system and their use reaches economies of scale. Still, there are a number of factors, such as the size, electrical efficiency, heating efficiency, government policies about emission, EENS reduction, and the fuel price that influence the results.

In this paper, a value-based planning method for CCHP placement has been proposed based on the energy hub concepts.

The proposed method, determines the best operational point of energy hub and the optimal size of CHP, absorption chiller, auxiliary boiler and heating storage devices with the maximum net benefit. To solve the problem the GAMS software is employed. Test results show that CCHP installation with suitable size is one of the best methods to improve service reliability and decrease the power cost overtly.

Future work may be extended with benefits, such as the type of manufacturer, type of technology, policies of the local utility, and seasonal effect on demand and load growth rate.

\section{Acknowledgments}

The authors would like to thank the Elite National Foundation and FiFi for their useful advices and financial support during this research.

\section{References}

[1] M. Rabinowitz, "Power Systems of the Future. I," IEEE Power Engineering Review, Vol. 20, No. 1, 2000, pp. 516. doi:10.1109/39.814649

[2] C. Mitchell, "The Value of Distributed Generation-Policy Implications for the UK," IEE Colloquium on Economics of Embedded Generation, London, 29 October1998, pp. 1/1-111.

[3] J.-H. Teng, Y.-H. Liu, C.-Y. Chen and C.-F. Chen, "Value-Based Distributed Generator Placements for Service Quality Improvements," Electrical Power and Energy 
Systems, Vol. 29, No. 3, 2007, pp. 268-274. doi:10.1016/j.ijepes.2006.07.008

[4] M. Geidl, "Integrated Modeling and Optimization of Multicarrier Energy Systems,” Doctoral and Habilitation Theses, Power Systems Laboratory, ETH, Zurich, 2007

[5] R. Billinton and R. N. Allen, "Reliability Evaluation of Engineering Systems, Concept and Techniques," 2nd Edition, Plenum Press, New York, 1992.

[6] R. Graham and W. Chow, "Technical and Economic Assessment of Combined Heat and Power Technologiesfor Commercial Customer Applications”, EPRI Project Manager, 2003.

[7] M. Geidl, G. Koeppel, P. Favre-Perrod, B. Klöckl, G. Andersson and K. Fröhlich, "Energy Hubs for the Futures," IEEE Power \& Energy Magazine, Vol. 5, No. 1, 2007, pp. 24-30.

[8] G. Koepple and G. Anderson, "The Influence of Combined Power, Gas and Thermal Networks on the Reliability of Supply," The Sixth World Energy System Conference, Torino, 10-12 July 2006, pp. 646-651.

[9] J. Teng, Y. Liu, C. Chen and C.-F. Chen, "Value-Based Distributed Generator Placements for Service Quality Improvements," International Journal of Electrical Power \& Energy Systems, Vol. 29, No. 3, 2007, pp. 268-274. doi:10.1016/j.ijepes.2006.07.008

[10] H. Asano and S. Bando, "Operational Planning Method and Economic Analysis of Microgrid with Intermittent Renewable Energy and Battery Storage," 29th IAEE International Conference, Potsdam, 7-10 June 2006.

[11] P. M. Costa and M. A. Matos, "Economic Analysis of Microgrids including Reliability Aspect," Internationl Conference on Probabilistic Methods Applied to Power System, Stockholm, 11-15 June 2006, pp. 1-8.

[12] B. Maurhoff and G. Wood, "Dispersed Generation Reduce Power Costsand Improve Service Reliability,” Rural Electric Power Conference, Louisville, May 2000, pp. C5/1$\mathrm{C} 5 / 7$.

[13] A. Silvestri, A. Berizzi and S. Buonanno, "Distributed Generation Planning Using Genetic Algorithms,” International Conference on Electric Power Engineering, 1999. PowerTech Budapest 99, Budapest, 29 August-2 September 1999, p. 257.

[14] A. S. Siddiqui, C. Marnay, O. Bailey and K. H. LaCommare, "Optimal Selection Of On-Site Generation with Combined Heat and Power Applications," International Journal of Distributed Energy Resources, Vol. 1, No. 1, 2005, pp. 33-62.

[15] A. R. Abdelaziz and W. M. Ali, "Dispersed Generation Planning Using a New Evolutionary Approach,” IEEE Bologna Power Tech Conference, Bologna, 23-26 June 2003, p. 5.

[16] J. A. Greatbanks, D. H. Popovic, M. Begovic, A. Pregelj, and T. C. Green, "On Optimization for Security and Reliability of Power Systems with Distributed Generation," IEEE Bologna Power Tech Conference, Bologna, 23-26 June 2003, p. 8.

[17] H. M. Groscurth, T. Bruckner and R. Kümmel, "Model- ing of Energy Service Supply System”, Energy, Vol. 20, No. 9, 1995, pp. 941-958. doi:10.1016/0360-5442(95)00067-Q

[18] I. Bouwmans and K. Hemmes, "Optimising Energy Systems-Hydrogen and Distributed Generation,” 2nd International Symposium on Power System Market Aspects, Stockholm, 2-4 October 2002.

[19] R. H. Lasseter and P. Piagi, "Microgrid: A Conceptual Solution,” IEEE 35th Annual Power Electronics Specialists Conference, Aachen, 20-25 June 2004, pp. 4285-4290.

[20] R. Frik and P. Favre-Perrod, "Proposal for a Multifunctional Energy Bus and Its Interlink with Generation and Consumption,” Diploma Thesis, Power Systems and High Voltage Laboratories, ETH, Zurich, 2004.

[21] M. Geidl, “A Greenfield Approach for Future Power Systems,” Proceedings of Cigre Session 41, Paris, 2006.

[22] J. Kanter, "Europe Considers New Taxes to Promote 'Clean' Energy,” The New York Times, 22 June 2010. http://www.nytimes.com/2010/06/23/business/energyenvi ronment/23carbon.html?_r=2\&ref=cap_and_trade

[23] A. Sheikhi, B. Mozafari and A. M. Ranjbar, "CHP Optimize Selection Methodology for a Multicarrier Energy System,” IEEE PowerTech Conference, Trondheim, 19-23 June 2011, pp. 1-7.

[24] D\&R, “2009 Buildings Energy Data Book,” D\&R International, Ltd., 2009.

[25] Y. J. Ruan, et al., "Optimal Option of Distributed Generation Technologies for Various Commercial Buildings," Applied Energy, Vol. 86, No. 9, 2009, pp. 1641-1653. doi:10.1016/j.apenergy.2009.01.016

[26] A. K. Basu and S. Chowdhury, "Impact of Strategic Deployment of CHP-Based DERs on Microgrid Reliability," IEEE Transactions on Power Delivery, Vol. 25, No. 3, 2010, pp. 1609-1705.

[27] H. Cho, "Evaluation of CCHP Systems Performance Based on Operational Cost, Primary Energy Consumption, and Carbon Dioxide Emission by Utilizing an Optimal Operation Scheme," Applied Energy, Vol. 86, No. 12, 2009, pp. 2540-2549. doi:0.1016/j.apenergy.2009.04.012

[28] A. Sheikhi, A. M. Ranjbar, M. Mahmoody and F. Safe, "CHP Optimize Selection Methodology for an Energy Hub System,” 2011 10th International Conference on Environment and Electrical Engineering, Rome, 8-11 May 2011, pp. 1-5.

[29] http://www.eia.doe.gov/oil_gas/natural_gas/info_glance/n atural_gas.html

[30] http://www.eia.doe.gov/cneaf/electricity/epm/table5_3.ht $\mathrm{ml}$

[31] “2008 ASHRAE Handbook-HVAC Systems and Equipment,” ASHRAE, 2008.

[32] C. Marnay, et al., "Optimal Technology Selection and Operation of Commercial-Building Microgrids," IEEE Transactions on Power Systems, Vol. 23, No. 3, 2008, pp. 975982. 